\title{
molecules
}

ISSN 1420-3049

(C) 2008 by MDPI

www.mdpi.org/molecules

Communication

\section{Novel Unsaturated Sucrose Ethers and Their Application as Monomers}

\author{
Carina C. Crucho, Krasimira T. Petrova*, Rui C. Pinto, and Maria T. Barros* \\ REQUIMTE, Departamento de Química - FCT, Universidade Nova de Lisboa, Quinta da Torre, 2829- \\ 516 Caparica, Portugal \\ * Authors to whom correspondence should be addressed; E-mails: krasimira.petrova@dq.fct.unl.pt; \\ mtbarros@dq.fct.unl.pt; Fax: (+)351212948550
}

Received: 5 March 2008; in revised form: 26 March 2008 / Accepted: 26 March 2008 / Published: 28 March 2008

\begin{abstract}
Novel unsaturated ethers were synthesised in good yields starting from sucrose, using a two-step mild and efficient procedure based on the Gassman method, which consists in forming a vinyl group by the elimination of ethanol from mixed acetals with trimethylsilyl trifluoromethanesulfonate in the presence of alkyl amines. Mixed acetals are readily obtained from the corresponding alcohols and ethyl vinyl ether, using an acidic catalyst. Conventional etherification involving a primary halide was also examined. The monomers thus obtained were successfully polymerised by a free radical mechanism, yielding unbranched linear and soluble polymers with pending sucrose moieties, and some of their physical properties were determined.
\end{abstract}

Keywords: Sustainable chemistry, vinyl sucrose ether monomers, biodegradable copolymers, natural products copolymers, free radical copolymerisation

\section{Introduction}

The demand for biodegradable plastics has increased over the past few decades, not only due to increasing environmental concerns, but also for their biomedical applications [1]. Sucrose is a low molecular weight carbohydrate feedstock from which it is possible to elaborate new materials [2], such as water-soluble and/or amphiphilic, biocompatible polymers [3] and other new compounds owing to 
their low price. Some applications for sugar based polymers are drug delivery systems, dental medicine, bio implants, contact lenses and tissue engineering [4, 5], and they have the advantage of being potentially biodegradable $[6,7]$. Obtaining polymers and copolymers from carbohydrate derived monomers is a work with a pronounced ecological aspect. The quest for novel, sustainable, but also structurally robust materials is gaining momentum as the pressure on our environment is building up and the progressive changeover of chemical industry to renewable feedstock for their raw materials emerges as an inevitable necessity. To achieve this goal we had proposed the introduction of sugar moieties in the macromolecules of conventional polyolefins by copolymerisation with vinyl carbohydrate derivatives $[8,9]$. Similar types of copolymers, obtained by attaching a sugar moiety to functionalised polyolefins, have been shown to display significantly improved biodegradability $[6,7]$.

In previous publications [8-14] we have reported the synthesis and applications of different sucrose esters. Since sucrose has eight chemically active hydroxyl groups, regioselective derivatisation is important in the selective synthesis of sucrose-containing linear polymers $[15,16]$. The route to selective derivatisation of the 6'-position of the sucrose has been developed in our laboratory [12, 13]. It allowed us to obtain the fully protected sucrose with only the 6'-hydroxyl unprotected. Protectiondeprotection strategies have been discussed by Jarosz et al. [17]. Another difficulty to be taken into account is the instability of the sucrose glycosidic bond under acidic conditions, which prevented us from adapting some efficient catalytic methods allowing the direct coupling of natural polyols with benzyl alcohols over solid acid catalysts, as recently reported [18].

Herein, we opted to explore the polymerisation activity of $\pi$-ether system attached to sucrose and we present the synthesis of novel unsaturated sucrose ethers, as well as an example for their successful free radical copolymerisation with styrene. For obtaining vinyl sucrose ether, we have adopted a new two-step route via mixed acetals, based on the Gassman method, first reported in 1993 [19], as it requires readily available reagents, mild conditions, and does not involve the use of heavy metal salts catalysts, like mercury [20]. It consists in forming a vinyl group by the elimination of ethanol from mixed acetals with trimethylsilyl trifluoromethanesulfonate (TMS-triflate) in the presence of alkyl amines. Mixed acetals are readily obtained from the corresponding alcohols and ethyl vinyl ether, using acidic catalysts.

\section{Results and Discussion}

Four unsaturated ether sucrose monomers were synthesised by different methods. The mixed acetal 4 was prepared by treating 3 (obtained as reported [8]) with ethyl vinyl ether in the presence of PPTS at r.t. for $2 \mathrm{~h}$. No side products were observed, and a mixture of diastereomers was produced, with no attempt at separation being made. After purification by flash column chromatography, the elimination reaction was performed by treating 4 with TMS-triflate and triethylamine at r.t. for $2 \mathrm{~h}$, leading to 5 (Scheme 1). The yield of this step was decreased by the competing side reaction of formation of silyl ether, resulting of a complexation of the trimethylsilyl cation with the sucrose connected oxygen atom, as it was discussed by Gassman et al. [14] and Hughes et al. [15]. Complexation of the trimethylsilyl cation with the ethoxy group oxygen produces the desired vinyl sucrose ether. 
Scheme 1. Synthesis of 1',2,3,3',4,4',6-hepta-O-benzyl-6'-O-vinyl sucrose (5).
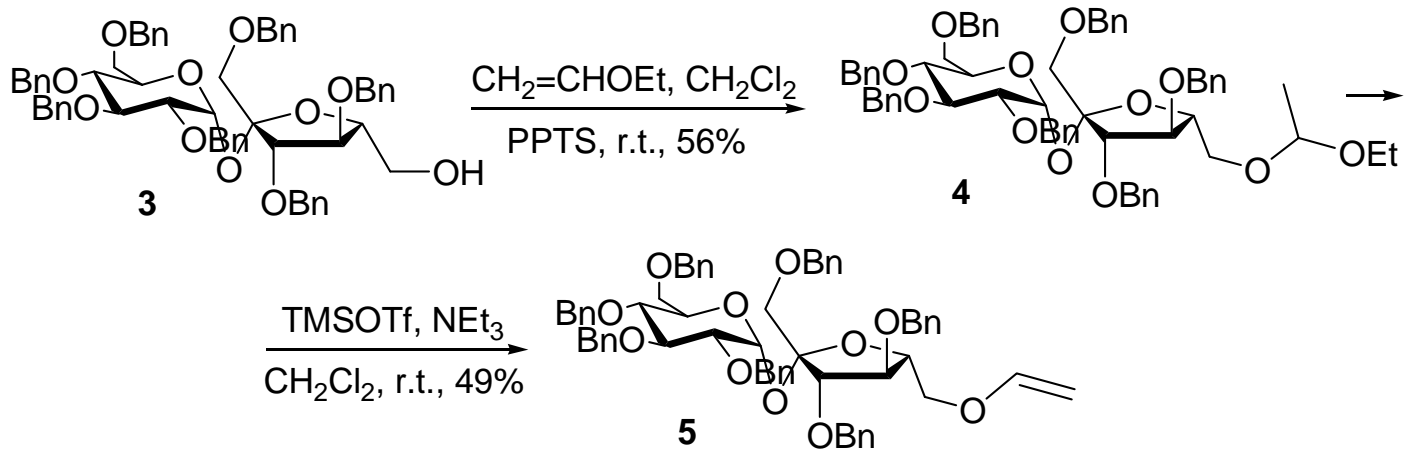

With the purpose of comparing the polymerisation ability of the monomer $\mathbf{5}$, in which the vinyl group is adjacent to the sucrose moiety, with similar ether compounds in which it is located farther away, we synthesised vinylbenzyl sucrose ethers 6-8, as previously reported [3]. We tested conventional etherification involving a primary halide, in our case 4-vinylbenzyl chloride, optimising the benzylation procedure for protected and unprotected sucrose. In the first case, the intermediate 3 was treated with $\mathrm{NaH}$ in DMF in the presence of phase-transfer catalyst at $0^{\circ} \mathrm{C}$, with the subsequent addition of the 4-vinylbenzyl chloride and increasing the temperature to $70^{\circ} \mathrm{C}$ (Scheme 2).

Scheme 2. Synthesis of 1',2,3,3',4,4',6-hepta-O-benzyl-6'-O-vinylbenzyl sucrose (6).

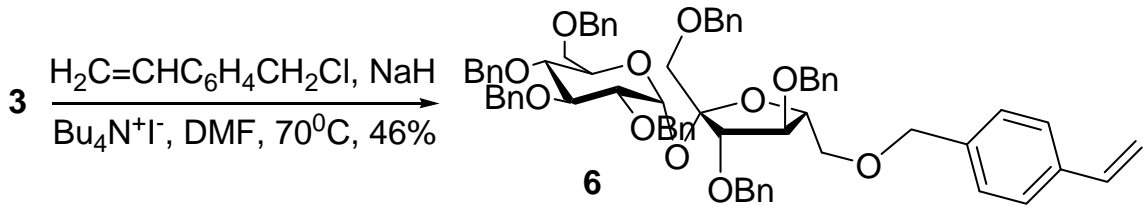

In order to obtain hydrophilic and amphiphilic polymers, we needed monomers with unprotected hydroxyl groups on the sucrose moiety. Those we achieved by reacting sucrose with 4-vinylbenzyl chloride under similar conditions, as described above. The reaction was monitored by TLC, and stopped at the first formation of diethers. A mixture of regioisomers of monovinylbenzyl ethers was isolated, with no attempt at separation being made. Subsequent acetylation was needed for detailed NMR analysis of the reaction products (Scheme 3 ).

Scheme 3. Synthesis of monovinylbenzyl sucrose and hepta-O-acetyl-monovinylbenzyl sucrose (8).
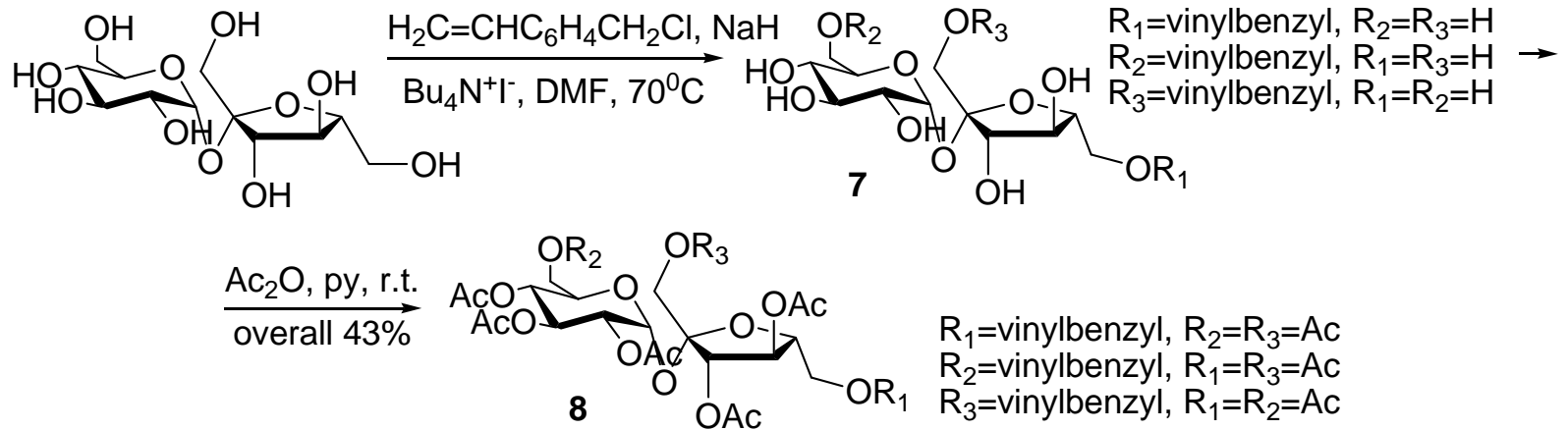
The regioselectivity question is a difficult one because of the complex chemistry of sucrose. In general, it is accepted that bulky substituents like TBDPS, are introduced at the primary positions in the order $6-\mathrm{OH} \approx 6$ ' $-\mathrm{OH}>1$ ' $-\mathrm{OH}[1]$. Molecular modeling of sucrose reveals the persistence of an intramolecular hydrogen bond of the 2-O ${ }^{\circ} \mathrm{HO}-1$ ' type in aprotic solvents [21], hence the 2-OH should be the most readily deprotonated under basic conditions, affording the 2-substituted derivative as the major product. In addition, the regioselectivity also depends on the nature of the electrophilic reagent, on the catalyst used for promoting the reaction and, not the least, on the solvent used.

In our case, when we compared the ${ }^{1} \mathrm{H}-\mathrm{NMR}$ and COSY spectra of the product and sucrose octaacetate, the signals for the $2-\mathrm{H}$ had exactly the same chemical shifts, while there were significant differences for the signals of the six methylene protons at the three primary positions. Although this assignment is not precise as we are dealing with a mixture of possible regioisomers, we concluded that most probably the substitution has taken place at the primary positions, the easiest accessible ones, although not the most reactive. The reason for that could be the presence of the phase transfer catalyst $\mathrm{Bu}_{4} \mathrm{~N}^{+} \mathrm{I}^{-}$, or a partial separation of the primary ethers, achieved during the purification in $43 \%$ global yield.

With thus obtained monomers example copolymerisation experiments were performed in organic medium, using toluene as a solvent, at $70^{\circ} \mathrm{C}$ in the presence of AIBN as a radical initiator (Table 1). The molar mass of the copolymers was measured by dynamic light-scattering, as Mark-HouwinkSakurada constants were estimated by calibration with commercial polystyrene standards. Copolymer compositions were calculated from ${ }^{1} \mathrm{H}$ NMR spectra by comparing the peak areas of aromatic styrene protons with the 14 sucrose unit protons.

Table 1. Experimental results for copolymerisation in toluene solutions of 5, 6, and 8 with styrene and the radical initiator $\mathrm{AIBN}, 70^{\circ} \mathrm{C}, 48 \mathrm{~h}$.

\begin{tabular}{|c|c|c|c|c|c|c|c|}
\hline & $\begin{array}{l}{[\mathbf{M}]_{0} /} \\
{[S]_{0}^{[a]}}\end{array}$ & $\begin{array}{l}{[\mathbf{M}] /} \\
{[\mathbf{S}]^{[\mathbf{b}]}}\end{array}$ & Yield [\%] $]^{[c]}$ & $M_{W}^{[d]}[g / m o l]$ & $\begin{array}{l}\varphi^{[\mathrm{e}]} \\
{[\mathrm{nm}]}\end{array}$ & $\alpha^{[f]}$ & $D^{[\mathrm{g}]}\left[\mathrm{cm}^{2} / \mathrm{s}\right]$ \\
\hline $5 / \mathrm{st}$ & 0.095 & 0.012 & 31 & 31900 & 654 & 0.288 & $5.57 .10-9$ \\
\hline $6 / \mathrm{st}$ & 0.090 & 0.040 & 36 & 6700 & 289 & 0.208 & $1.26 .10-8$ \\
\hline $8 / \mathrm{st}$ & 0.103 & 0.091 & 51 & 89500 & 1121 & 0.251 & $3.25 .10-9$ \\
\hline
\end{tabular}

[a] Initial mol ratio of the monomers. [b] Mole ratio of the comonomers in the copolymer, determined by ${ }^{1} \mathrm{H}-\mathrm{NMR}$. [c] Overall conversion of the monomers. [d] Calculated from the MHS equation from the diffusion coefficient D, measured by light-scattering. MHS coefficients were estimated by calibration with monodisperse polystyrene standards, $\mathrm{a}=-0.52, \mathrm{~K}=1.245 .10^{-6}$. [e] Effective diameter, determined by light-scattering. [f] Polydispersity (value, provided by the lightscattering method, it is close to zero for monodisperse samples, small (0.020 to 0.080$)$ for narrow distributions, and larger for broader distributions). [g] Diffusion coefficient. 
As we can see, copolymers with good sucrose derivative incorporation rates and high molecular mass were obtained. With monomer 5 , in which the double bond is very close to the bulky sucrose moiety and as expected, is impeding the polymerisation, we have lower incorporation of the sugar monomer, but nevertheless high molecular mass for this type of polymers. Under the conditions chosen, we achieved good overall conversions, compared to the reported in the literature [3], lower incorporation of sugar, which is probably result of the longer polymerisation times, and higher average molecular mass. The optimisation of the polymerisation procedure with a view to possible applications, as well as the biodegradability of copolymers, containing sucrose moieties side groups, is under investigation.

\section{Conclusions}

In summary, novel unsaturated ethers of sucrose were synthesised using a two-step mild and efficient procedure based on the Gassman method, as well as conventional etherification involving a primary halide. As an example application, the products were successfully polymerised by a free radical mechanism, yielding unbranched linear polymer materials with pending sucrose moieties, and some of their physical properties were determined.

\section{Experimental}

\section{General}

Reagents and solvents were purified before use [22]. NMR spectra were recorded at $400 \mathrm{MHz}$ on a Bruker AMX-400 instrument using $\mathrm{CDCl}_{3}$ as solvent. Chemical shift values $(\delta)$ are given in ppm downfield from TMS. The IR spectra were recorded on a Perkin-Elmer FTIR-1600 spectrophotometer. Average molecular weights were determined using a Brookhaven model BI-90 dynamic lightscattering apparatus, with operational angle $90^{\circ}$, calculated from the diffusion coefficients of polymer solutions suspended in ethanol, at $20^{\circ} \mathrm{C}$. All solvents used for dilution were filtered through a 0.2 micron membrane filter. 2,500 experimental cycles were used for each run, and the dust cut off, above 21 , had no effect on the measurement, indicating a reasonably dust-free sample. The calibration was performed with monodisperse polystyrene standards purchased from Aldrich.

\section{Synthesis of the mixed acetal 1',2,3,3',4,4',6-hepta-O-benzyl-6'-O-(1-ethoxy)ethyl sucrose (4)}

To a solution of 3 [8] (1.016 g; $1.045 \mathrm{mmol})$ in dry $\mathrm{CH}_{2} \mathrm{Cl}_{2}(10 \mathrm{~mL})$ were added PPTS $(10 \mathrm{mg})$ and ethylvinyl ether $(1.5 \mathrm{eq}, 0.5 \mathrm{~mL})$. The reaction mixture was stirred at r.t. for $2 \mathrm{~h} . \mathrm{NaHCO}_{3}(1 \mathrm{~g})$ was added, and stirred for $10 \mathrm{~min}$ more, filtered, concentrated and purified by flash column chromatography on silica gel $60(0.04-0.06 \mathrm{~mm})$, eluent: hex/EtOAc 3:1. Compound 4 was obtained as a light yellow oil (0.610 g, 56\%); Rf 0.40 (hex/EtOAc 3:1); IR: $v_{\max }\left(\mathrm{CH}_{2} \mathrm{Cl}_{2}\right)$ 3088, 3040, 3030, 2976, 2897, 2867, 2000-1600, 1496, 1454, 1363, 1266, 1208, 1082, 1028, 736, $698 \mathrm{~cm}^{-1}$; ${ }^{1} \mathrm{H}-\mathrm{NMR}: \delta_{\mathrm{H}}$ $\left(\mathrm{CDCl}_{3}\right) 9.79(1 \mathrm{H}, \mathrm{qd} J 2.13 \mathrm{~Hz}, \mathrm{CH}), 7.33-7.20(32 \mathrm{H}, \mathrm{m}, \mathrm{Ar}-\mathrm{H}), 7.12-7.10(2 \mathrm{H}, \mathrm{m}, \mathrm{Ar}-\mathrm{H}), 5.54(1 \mathrm{H}, \mathrm{d}$ $J 2.5 \mathrm{~Hz}, \mathrm{H}-1), 4.92-4.28\left(16 \mathrm{H}, \mathrm{m}, \mathrm{CH}_{2}-\mathrm{Ph}, \mathrm{H}-5\right.$ ' and $\left.\mathrm{H}-3\right), 4.09-4.06$ (1H, m, H-6), 4.03-3.97 (2H, m, 
H-4' and H-3'), 3.87-3.80 (1H, m, H-6'), 3.73-3.63 (4H, m, H-2, H-1' and $\left.\mathrm{OCH}_{2} \mathrm{CH}_{3}\right), 3.61-3.51$ (4H, m, H-5, H-1', H-6' and H-4), 3.48 (1H, d J 3.03 Hz, H-6), 2.20 (1H, d J 2.13 Hz, CHCH $), 1.27-1.19$ $\left(4 \mathrm{H}, \mathrm{m}, \mathrm{CH}_{2} \mathrm{CH}_{3}\right)$ ppm; confirmed by COSY and HMQC; ${ }^{13} \mathrm{C}-\mathrm{NMR}$ : $\delta_{\mathrm{C}}\left(\mathrm{CDCl}_{3}\right) 128.3(\mathrm{Ph}), 128.0$ (Ph), $127.9(\mathrm{Ph}), 127.8(\mathrm{Ph}), 127.7(\mathrm{Ph}), 127.5(\mathrm{Ph}), 103.8$ (C-2'), $91.1(\mathrm{C}-1), 83.6\left(\mathrm{C}-5\right.$ '), $81.8\left(\mathrm{C}-3^{\prime}\right)$, 81.2 (C-4'), 79.5 (C-3), 79.4 (C-5), 77.3 (C-2), $75.6\left(\mathbf{C H}_{2}-\mathrm{Ph}\right), 74.9\left(\mathbf{C H}_{2}-\mathrm{Ph}\right), 73.5\left(\mathbf{C H}_{2}-\mathrm{Ph}\right), 73.4$ $\left.\left(\mathrm{CH}_{2}-\mathrm{Ph}\right), 73.3\left(\mathrm{CH}_{2}-\mathrm{Ph}\right), 72.9\left(\mathrm{CH}_{2}-\mathrm{Ph}\right), 72.5\left(\mathrm{CH}_{2}-\mathrm{Ph}\right), 71.3(\mathrm{C}-4), 71.2(\mathrm{C}-6)\right), 67.9(\mathrm{C}-1$ ') $), 61.2(\mathrm{C}-$ 6), $60.6\left(\mathrm{OCH}_{2} \mathrm{CH}_{3}\right), 20.0\left(\mathrm{O}_{2} \mathrm{CHCH} 3\right), 15.3\left(\mathrm{OCH}_{2} \mathrm{CH}_{3}\right) \mathrm{ppm}$; confirmed by DEPT.

\section{1',2,3,3 ',4,4',6-hepta-O-benzyl-6'-O-vinyl sucrose (5)}

To a solution of $4(0.797 \mathrm{~g} ; 0.763 \mathrm{mmol})$ in dry $\mathrm{CH}_{2} \mathrm{Cl}_{2}(7 \mathrm{~mL})$ were added $\mathrm{Et}_{3} \mathrm{~N}(0.12 \mathrm{~mL}, 0.839$ $\mathrm{mmol})$ and TMSOTf $(0.15 \mathrm{~mL}, 0.839 \mathrm{mmol})$ at $0^{\circ} \mathrm{C}$. After $10 \mathrm{~min}$ it was allowed to warm to r.t. and stirred for $2 \mathrm{~h}$. The reaction mixture was neutralised with $1 \mathrm{~N} \mathrm{NaOH}(4 \mathrm{~mL})$, and extracted with diethyl ether $(3 \times 20 \mathrm{~mL})$. After drying and concentrating, it was purified by flash column chromatography on silica gel 60 (0.04-0.06 mm), eluent: hex/EtOAc 3:1. Compound 5 was obtained as a light yellow oil (0.250 g, 31\%); Rf 0.5 (Hex/AcOEt 3:1); IR: $v_{\max }\left(\mathrm{CH}_{2} \mathrm{Cl}_{2}\right)$ 3088, 3064, 3030. 2909, 2869, 1737, 2000 1600, 1497, 1454, 1361, 1243, 1209, 1096, 910, 737, $698 \mathrm{~cm}^{-1} ;{ }^{1} \mathrm{H}-\mathrm{NMR}: \delta_{\mathrm{H}}\left(\mathrm{CDCl}_{3}\right) 7.31-7.26(35 \mathrm{H}$, m, Ar-H), 7.16-7.14 (1H, m, Ar-H), $6.49(1 \mathrm{H}, \mathrm{dd} J 10.73$ e $5.1 \mathrm{~Hz}, \mathrm{OCH}=), 5.67(1 \mathrm{H}, \mathrm{d} J 2.6 \mathrm{~Hz}, \mathrm{H}-1)$, $4.93\left(1 \mathrm{H}, \mathrm{d} J 8.16 \mathrm{~Hz}, \mathrm{CH}_{2}-\mathrm{Ph}\right), 4.83\left(1 \mathrm{H}, \mathrm{d} J 8.19 \mathrm{~Hz}, \mathrm{CH}_{2}-\mathrm{Ph}\right), 4.77$ (1H, d $\left.J 8.16 \mathrm{~Hz}, \mathrm{CH}_{2}-\mathrm{Ph}\right)$, 4.68-4.38 (12H, m, CH $\boldsymbol{H}_{2}-\mathrm{Ph}$ and $\mathrm{H}-5$ ') $4.20\left(1 \mathrm{H}, \mathrm{dd} J 10.8\right.$ and $\left.1.41 \mathrm{~Hz},=\mathrm{CH}_{2 \text { trans }}\right), 4.18-4.15(1 \mathrm{H}, \mathrm{m}$, H-3'), 4.10-4.05 (1H, m, H-4), 4.01 (1H, dd $J 5.1$ and $1.44 \mathrm{~Hz},=\mathrm{CH}$ 2is $), 3.97-3.92$ (1H, m, H-4'), 3.86-3.81 (1H, m, H-6), 3.75 (1H, m, H-6), 3.64 (1H, t J 7.17 Hz, H-2), 3.56-3.49 (3H, m, H-5, H-1' and H-6'), $3.42\left(1 \mathrm{H}\right.$, dd $J 7.1$ and $1.2 \mathrm{~Hz}, \mathrm{H}-6$ ') ppm; confirmed by COSY and HMQC; ${ }^{13} \mathrm{C}-\mathrm{NMR}: \delta_{\mathrm{C}}$ $\left(\mathrm{CDCl}_{3}\right) 151.6(\mathrm{OCH}=), 128.3(\mathrm{Ph}), 128.3(\mathrm{Ph}), 127.9(\mathrm{Ph}), 127.8(\mathrm{Ph}), 127.7(\mathrm{Ph}), 127.6(\mathrm{Ph}), 127,5$ $(\mathrm{Ph}), 104.6\left(\mathrm{C}-2^{\prime}\right), 90.2(\mathrm{C}-1), 86.9\left(=\mathrm{CH}_{2}\right), 83.9(\mathrm{C}-5$ '), 81.8 (C-3'), 81.2 (C-4'), 79.5 (C-3), $79.4(\mathrm{C}-$ 5), $77.3(\mathrm{C}-2), 75.6\left(\mathbf{C H}_{2}-\mathrm{Ph}\right), 74.8\left(\mathbf{C H}_{2}-\mathrm{Ph}\right), 73.4\left(\mathbf{C H}_{2}-\mathrm{Ph}\right), 72.9\left(\mathbf{C H}_{2}-\mathrm{Ph}\right), 72.6\left(\mathbf{C H}_{2}-\mathrm{Ph}\right), 72.3$ $\left(\mathrm{CH}_{2}-\mathrm{Ph}\right), 71.0$ (C-6'), 70.6 (C-4), 69.1 (C-1'), 69.5 (C-6) ppm; confirmed by DEPT.

\section{l',2,3,3',4,4',6-hepta-O-benzyl-6'-O-vinylbenzyl sucrose (6)}

To a solution of $3(0.5 \mathrm{~g}, 0.514 \mathrm{mmol})$ in DMF $(12.5 \mathrm{~mL})$ were added a catalytic amount of $\mathrm{Bu}_{4} \mathrm{~N}^{+} \mathrm{I}^{-}$and $\mathrm{NaH}(0.07 \mathrm{~g}, 1.0 \mathrm{eq})$ at $0^{\circ} \mathrm{C}$. After $20 \mathrm{~min}, 4$-vinylbenzyl chloride $(0.09 \mathrm{~mL}, 1.0 \mathrm{eq})$ was added, the ice-bath removed, and the reaction mixture was heated at $70^{\circ} \mathrm{C}$ for $4 \mathrm{~h}$. Concentrated and purified by flash column chromatography on silica gel $60(0.04-0.06 \mathrm{~mm})$, eluent hex/EtOAc 3:1. Compound 6 was obtained as a light yellow oil $(0.260 \mathrm{~g}, 46 \%)$; $f$ 0.7 (hex/AcOEt 3:1); ${ }^{1} \mathrm{H}-\mathrm{NMR}$ : $\delta_{\mathrm{H}}$ $\left(\mathrm{CDCl}_{3}\right)$ 7.28-7.12 (39H, m, Ar-H), $6.65(1 \mathrm{H}, \mathrm{dd} J 13.2$ e $8.2 \mathrm{~Hz}, \mathrm{PhCH}=), 5.71-5.66(2 \mathrm{H}, \mathrm{m}, \mathrm{H}-1$, $\left.=\mathrm{CH}_{2 \text { trans }}\right), 5.20\left(1 \mathrm{H}, \mathrm{dd}, J 10.8\right.$ e $\left.2.11 \mathrm{~Hz}=\mathrm{CH}_{2 \mathrm{cis}}\right), 4.86-4.35\left(16 \mathrm{H}, \mathrm{m}, 7\left(\mathbf{C H}_{2}-\mathrm{Ph}\right), \mathrm{H}-5\right.$ ', $\left.\mathbf{C H}_{2}-\mathrm{Ph}\right)$, 4.22-3.84 (4H, m, H-6' ' , H-6' ', , H-5, H-4', H-3), 3.71-3.25 (7H, m, H-2, H-6 ${ }_{\mathrm{a}}, \mathrm{H}-6_{\mathrm{b}}, \mathrm{H}-1$ ' ${ }_{\mathrm{a}}, \mathrm{H}-1$ ' ${ }_{\mathrm{b}}, \mathrm{H}-4$, H-3') ppm; confirmed by COSY and HMQC; ${ }^{13} \mathrm{C}-\mathrm{NMR}: \delta_{\mathrm{C}}\left(\mathrm{CDCl}_{3}\right) 138.9(\mathrm{Ar}-\mathrm{C}), 138.6(\mathrm{Ar}-\mathrm{C})$, 138.2 (Ar-C), 138.0 (Ar-C), 137.9 ( $\mathrm{PhCH}=), 136.8$ (Ar-C), 136.5 (Ar-C), 128.3 (Ar-CH), 128.3 (ArCH), 128.0 (Ar-CH), 127.9 (Ar-CH), 127.7 (Ar-CH), 127.6 (Ar-CH), 127.5 (Ar-CH), 126,2 (Ar), $113.7\left(\mathrm{CH}_{2}=\right)$, $104.6\left(\mathrm{C}-2^{\prime}\right), 89.9(\mathrm{C}-1), 83.9\left(\mathrm{C}^{\prime} 5^{\prime}\right), 82.4\left(\mathrm{CH}_{2}-\mathrm{Ph}\right), 81.9(\mathrm{C}-3), 81.9$ (C-4'), $79.8(\mathrm{C}-$ 
3'), 79.6 (C-5), 77.6 (C-2), $75.5\left(\mathrm{CH}_{2}-\mathrm{Ph}\right), 74.8\left(\mathrm{CH}_{2}-\mathrm{Ph}\right), 73.4\left(\mathbf{C H}_{2}-\mathrm{Ph}\right), 73.0\left(\mathbf{C H}_{2}-\mathrm{Ph}\right), 72.5\left(\mathrm{CH}_{2^{-}}\right.$ $\mathrm{Ph}), 72.2\left(\mathrm{CH}_{2}-\mathrm{Ph}\right), 71.4$ (C-6'), 71.2 (C-6), 70.6 (C-4), 68.4 (C-1') ppm; confirmed by DEPT.

Hepta-O-acetyl-monovinylbenzyl sucrose (8).

To a solution of sucrose $(1.000 \mathrm{~g}, 2.9 \mathrm{mmol})$ in DMF $(25 \mathrm{~mL})$ were added a catalytic amount of $\mathrm{Bu}_{4} \mathrm{~N}^{+} \mathrm{I}^{-}$and $\mathrm{NaH}(0.14 \mathrm{~g}, 1.1 \mathrm{eq})$ at $0^{\circ} \mathrm{C}$. After $20 \mathrm{~min}$, 4-vinylbenzyl chloride $(0.45 \mathrm{ml}, 1.1 \mathrm{eq})$ was added, the ice-bath removed, and the reaction mixture was heated at $70^{\circ} \mathrm{C}$ for $4 \mathrm{~h}$. After removing the solvent, the residue was dissolved in pyridine, acetic anhydride $(3 \mathrm{~mL})$ was added, and the mixture stirred overnight. Concentrated and purified by flash column chromatography on silica gel 60 (0.04$0.06 \mathrm{~mm}$ ), eluent hex/EtOAc 1:1. Compound 8 was obtained as a light yellow oil (0.934 g, 43\%); R $f$ 0.7 (hex/AcOEt 1:2); IR: $v_{\max }\left(\mathrm{CH}_{2} \mathrm{Cl}_{2}\right)$ 3059, 2962, 2121, 1746, 1513, 1432, 1370, 1230, 1168, 1104 , 1046, 910, 829, 737, 703, $601 \mathrm{~cm}^{-1}$; ${ }^{1} \mathrm{H}-\mathrm{NMR}: \delta_{\mathrm{H}}\left(\mathrm{CDCl}_{3}\right)$ 7.56-7.43 $(2 \mathrm{H}, \mathrm{m}, \mathrm{Ar}-\mathrm{H}), 7.27-7.21(2 \mathrm{H}, \mathrm{m}$, Ar-H), $6.71(1 \mathrm{H}$, dd $J 13.2$ e $8.2 \mathrm{~Hz}, \mathrm{PhCH}=), 5.75\left(1 \mathrm{H}, \mathrm{dd} J 13.2\right.$ e $\left.4.02 \mathrm{~Hz},=\mathrm{CH}_{2 \text { trans }}\right), 5.72-5.65$ (1H, m, H-1), 5.56-5.5 (1H, m, H-4'), 5.42 (1H, t J $6.56 \mathrm{~Hz}, \mathrm{H}-3), 5.40-5.36$ (1H, m, H-3), 5.30 (1H, s, $\left.\mathrm{PhCH}_{2}\right), 5.27\left(1 \mathrm{H}\right.$, dd $J 9.14$ e $\left.3.48 \mathrm{~Hz},=\mathrm{CH}_{2 \mathrm{cis}}\right), 5.05(1 \mathrm{H}, \mathrm{m}, \mathrm{H}-4), 4.88-4.81(1 \mathrm{H}, \mathrm{dd}, \mathrm{H}-2), 4.66-$

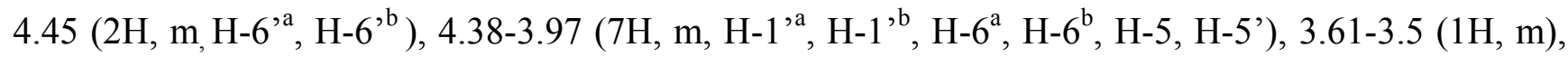
2.16-1.90 $\left(21 \mathrm{H}, \mathrm{m}, \mathrm{CH}_{3}(\mathrm{C}=\mathrm{O})\right)$ ppm; confirmed by COSY and HMQC; ${ }^{13} \mathrm{C}-\mathrm{NMR}: \delta_{\mathrm{C}}\left(\mathrm{CDCl}_{3}\right)$ 170.7$169.8\left(\mathrm{CH}_{3}(\mathrm{C}=\mathrm{O})\right), 137.5$ (Ar), 137.3 (Ar), 137.0 (Ar), 136.7 (Ar), $136.4(\mathrm{PhCH}=), 128.8$ (Ar), 128.5 (Ar), 128.3 (Ar), $128.0(\mathrm{Ar}), 126.4(\mathrm{Ar}), 126.3(\mathrm{Ar}), 114.0\left(\mathrm{CH}_{2}=\right), 113.8\left(\mathbf{C H}_{2}=\right), 104.5(\mathrm{C}-2$ ') $), 103.6$ (C-2'), 90.3 (C-1), 89.6 (CH2-Ph), 78.8 (C-5'), 78.5 (C-5'), 75.8 (C-3), 75.4 (C-4'), 74.6 (C-3'), 73.4 (C-6'), 72.5 (C-6), 71.7 (C-2), 70.2 (C-1'), 68.5-68.3 (C-4 and C-5), 63.7-63.3 (C-6 and C-6'), 61.9 $\left(\mathrm{C}-1^{\prime}\right), 61.7\left(\mathrm{C}-1^{\prime}\right), 20.7\left(\mathrm{CH}_{3}(\mathrm{C}=\mathrm{O})\right)$ ppm; confirmed by DEPT.

General procedure for free radical copolymerisations of monomers $\mathbf{5 , 6}$, and $\mathbf{8}$ with styrene

Copolymerisations were carried out in anhyd. toluene solutions $(0.1 \mathrm{M})$ in the presence of AIBN as radical initiator ( $1 \%$ by weight with respect to the monomer mixture). Dissolved oxygen was removed from the solutions by sparging with argon. They were then heated at $70^{\circ} \mathrm{C}$ for $48 \mathrm{~h}$, and the solutions were then cooled to r.t. and the product precipitated in cold EtOH. The white solid was filtered and washed several times with cold EtOH. The polymers were purified by repeated dissolution in toluene and reprecipitation in cold EtOH and dried under vacuum.

\section{Acknowledgements}

This work has been supported by Fundação para a Ciência e a Tecnologia (SFRH/BPD/9474/2002 and PTDC/QUI/72120/2006).

\section{References}

1. Lichtenthaler, F. W.; Peters, S., Carbohydrates as green raw materials for the chemical industry. Compt. Rend. Chim. 2004, 7, 65-90. 
2. Queneau, Y.; Jarosz, S.; Lewandowski, B.; Fitremann, J., Sucrose chemistry and applications of sucrochemicals. Adv. Carbohydr. Chem. Biochem. 2008, 61, 217-292

3. Jhurry, D.; Deffieux, A.; Fontanille, M., Sucrose based polymers. Linear polymers with sucrose side-chains. Makromol.Chem. 1992, 193, 2997-3007.

4. Satomi, M.; Sogawa, S., Hard coating layer for coated products useful in pharmaceuticals and foodstuffs, contains sugar, and reduced amylolysis product containing sugar composition of hydrogenated saccharides with varying polymerization degree. JP2007053952-A, 2007.

5. Popplewell, L. M.; Henson, L., Method useful to deliver active ingredient to cleaning composition involves preparing structured material of hydrophilic particle, hydrophobic active ingredient and polyhydric material; and providing the structured material into composition. US2007048339-A1, 2007.

6. Galgali, P.; Varma, A. J.; Puntambekar, U. S.; Gokhale, D. V., Towards biodegradable polyolefines: strategy of anchoring minute quantities of monosaccharides and disaccharides onto functionalized polystyrene, and their effect on facilitating polymer biodegradation. Chem. Commun. 2002, 2884-2885.

7. Tokiwa, Y.; Fan, H.; Hiraguri, Y.; Kurane, R., Biodegradation of a sugar branched polymer consisting of sugar, fatty acid, and poly(vinyl alcohol). Macromolecules 2000, 33, 1636-1639.

8. Barros, M. T.; Petrova, K.; Ramos, A. M., Regioselective Copolymerization of Acryl Sucrose monomers. J. Org. Chem. 2004, 69, 7772-7775.

9. Barros, M. T.; Petrova, K. T.; Ramos, A. M., Biodegradable Polymers based on $\alpha$ - or $\beta$-Pinene and Sugar Derivatives or Styrene, Obtained under Normal Conditions and Microwave Irradiation. Eur. J. Org. Chem. 2007, 1357-1363.

10. Barros, M. T.; Maycock, C. D.; Rodrigues, P.; Thomassigny, C., Improved anomeric selectivity for the aroylation of sugars. Carbohydr. Res. 2004, 339, 1373-1376.

11. Andrade, M. M.; Barros, M. T., Facile conversion of O-sylil protected sugars into their corresponding formates using POCl3.DMF complex. Tetrahedron 2004, 60, 9235-9243.

12. Barros, M. T.; Maycock, C. D.; Sineriz, F.; Thomassigny, C., Fast galloylation of a sugar moiety: preparation of three monogalloylsucroses as references for antioxidant activity. A method for the selective deprotection of tert-butyldiphenylsilyl ethers. Tetrahedron 2000, 56, 6511-6516.

13. Barros, M. T.; Sineriz, F., Synthesis of optically active monomers and copolymers derived from protected 6'-O-acryloyl sucroses. Synthesis 2002, 10, 1407-1411.

14. Andrade, M. M.; Barros, M. T.; Rodrigues, P., Selective Synthesis Under Microwave Irradiation of Carbohydrate Derivatives Containing Unsaturated Systems. Eur. J. Org. Chem. 2007, 36553668.

15. Fanton, E.; Fayet, C.; Gelas, J.; Deffieux, A.; Fontanille, M.; Jhurry, D., Synthesis of 4-O- and 6O-monoacryloyl derivatives of sucrose by selective hydrolysis of 4,6-O-(1-ethoxy-2propenylidene)sucrose. Polymerisation and copolymerisation with styrene. Carbohydr. Res. 1993, 240, 143-152.

16. Potier, P.; Bouchou, A.; Descotes, G.; Queneau, Y., Proteinase N-catalysed transesterifications in DMSO-water and DMF-water: preparation of sucrose monomethacrylate. Tetrahedron 2000, 41, 3597-3600. 
17. Jarosz, S.; Mach, M., Regio- and Stereoselective Transformations of Sucrose at the Terminal Positions. Eur. J. Org. Chem. 2002, 769-780.

18. Gu, Y.; Azzouzi, A.; Pouilloux, Y.; Jerome, F.; Barrault, J., Heterogeneously catalyzed etherification of glycerol: new pathways for transformation of glycerol to more valuable chemicals. Green Chem. 2008, 10, 164-167.

19. Gassman, P. G.; Burns, S. J.; Pfister, K. B., Synthesis of cyclic and acyclic enol ethers (vinyl ethers). J. Org. Chem. 1993, 58, 1449-1457.

20. Hughes, K. D.; Nguyen, T.-L. N.; Dyckman, D.; Dulay, D.; Boyko, W. J.; Giuliano, R., Synthesis of vinyl alpha-D-glucopyranosides from mixed acetal glycosides. Tetrahedron: Asymmetry 2005, 16, 273-282.

21. Lichtenthaler, F. W.; Immel, S.; Kreis, U. Carbohydrates as Organic Raw Materials. VCH Verlagsgessellschaft mbH: Weinheim, 1991; Chapter 1, pp.1-32.

22. Perrin, D. D.; Armagedo, W. L. F.; Perrin, D. R., Purification of Laboratory Chemicals, 2 nd Ed. Pergamon Press Ltd.: New York, 1980.

Sample availability: Samples of all compounds synthesised herein are available from the authors upon request.

(C) 2008 by MDPI (http://www.mdpi.org). Reproduction is permitted for noncommercial purposes. 